\title{
Medical Therapy of Burn Scar Before Any Plastic Surgery by Using Topical Corticosteroid Combined with Oral Zinc Sulfate
}

\author{
(1) Khalifa E. Sharquie', (1) Raed I. Jabbar ${ }^{2}$ \\ 1University of Baghdad, College of Medicine, Medical City Teaching Hospital, Department of Dermatology, Baghdad, Iraq \\ 2Al-Anbar Health Directorate, Fallujah Teaching Hospital, Department of Dermatology, Anbar, Iraq
}

\section{ABSTRACT}

Background: Burn scar is one of the commonest medical problems that need intervention as initially treat burn infection, then preventing the scar, followed by treatment of scar.Plastic surgery interference should be considered as a last resort.

Materials and Methods: This is case series descriptive and therapeutic interventional study where a total of 170 patients with burn scar were managed and evaluated. Their ages ranged from 1-40 years with a mean 25 year, 120 (70.58\%) males and 50 (29.41\%) females. All had history of burn and the age of scar was ranged from 0.5-3 years. All cases were treated with topical diluted clobetasol ointment combined with oral zinc sulfate with duration of 2-4 months. Scoring system of reduction of burn scar was introduced and applied and three parameters of response were considered: scar size reduction, improvement of itching and pigmentation whether hyper or hypopigmentation. The reduction in scoring was estimated as mild, moderate and marked reduction.

Results: The results of this study showed $50 \%$ reduction rate while scoring system demonstrated statistically significant reduction with $p$ value $\leq 0.001$ at two months of therapy. While at four months, there was $75 \%$ reduction rate and with highly statistically significant reduction of scoring system $p$ value $\leq 0.0001$. The reduction of scar scoring was mild in $20 \%$ of cases and moderate in $30 \%$ while marked in $50 \%$ of patients at the end of four months of therapy.

Conclusion: Medical therapeutic intervention should be started as early as possible to minimize scar formation, to reduce the scar size and treat pigmentary problems. This therapeutic trial will minimize plastic surgery need. Also newly invented scoring system was introduced to evaluate the response to treatment.

Keywords: Burn scar, Corticosteroid, Zinc sulfate, Plastic surgery

\section{Introduction}

Although there is great improvement in acute burn management still there is considerable unmet problem in burn recovery and skin scarring and the prevalence of hypertrophic scarring following burn is about $70 \%$ [1].

After skin burn injury, there is linear deposition of collagen that develops a scar that lacks the pliability of normal skin. This collagen deposition happens in excess resulting in the appearance of a pathological scar that is thick and hard [2]. Furthermore, the scar is painful and pruritic which worsens the patient outcome and quality of life [3]. There are two types of scarring that originate from burn trauma-keloid or hypertrophic scar. Keloids, develop months to years after initial injury and spread beyond the margin of the original defect. It continues to evolve over time, without a quiescent or regressive phase and do infiltrate the surrounding tissue [4]. Hypertrophic scars on the other hand, happen within the 
borderlines of the original defect, are raised, red to pink in color, and appear within 4-8 weeks after initial trauma or injury [5]. This scar will mature and gradually regress to a flatter scar over a period of two years. Like keloid, hypertrophic scars are raised and erythematous. In both keloids and hypertrophic scarring there is increased collagen deposition that is oriented in thick bundles, however, the arrangement of collagen fibers differs. Keloids are primarily composed of disorganized bundles of type 1 and type 3 collagen arranged haphazardly to the epithelium surface [6]. In contrast, in hypertrophic scarring, histology reveals a profusion of collagen type 3 fibers oriented parallel to the surface of the epithelium [6].

The formation of pathological scars is regarded as a result of dysregulation in the process of wound healing which characterizes by an inflammatory phase, a proliferative phase, and a remodeling phase [5,7]. The inflammation is critical to the removal of dead tissue and the prevention of infection by neutrophils and macrophages through the secretion of cytokines and proteases and the actions of phagocytosis [8]. The proliferation phase was finished by the migration and proliferation of different cells. Activated by the cytokines and growth factors, such as platelet-derived growth factor and transforming growth factor-beta (TGF- $\beta$ ) released mainly from macrophages, fibroblasts are stimulated to produce extracellular matrix and collagen. Angiogenesis is initiated by the action of endothelial cells in response to the up regulation of vascular endothelial growth factor [9]. Keratinocytes from the border of the wound and adnexal structures migrate and proliferate to make the wound healed by re-epithelialization. While the remodeling phase can take up to a year or longer to complete, which is characterized by the replacement of collagen 3 by collagen 1 , rearrangement of granulation tissue, and the contracture of the scar through the action of myofibroblasts. During the remodeling phase, a variety of extracellular matrix and their corresponding enzyme system act to obtain the aim of restoring normal histological structure [10]. Even after remodeling for many years, the wounded tissue never regains the characteristics of normal skin. The dysregulation of apoptosis and proliferation of fibroblasts, a disproportion between synthesis and degradation collagen in the extracellular matrix, and abnormal structure of epithelium are responsible for scarring [11]. The early stage scars have extreme abnormally arranged collagen fibers and diffuse capillaries in histology, which manifest as a red hypertrophic scars, whereas the late stage of scars has excessive fiber deposition and blocked vessels, which manifest as normal color or reduced color scars with elevation, flat, or atrophy in morphology [11].

\section{Treatment of Burn Scar}

Non-invasive options: Which include use of compression treatment (such as pressure garments with or without gel sheeting); static and dynamic splints; acrylic casts; masks and clips; application of a variety of creams, oils and lotions, silicon sheeting, with or without adhesive and hydrotherapy $[1,12,13,14]$.

Invasive treatments: Include surgical excision and resuture [7]. Intralesional steroid injection [15] is commonly used but is prone to complications like dermal thinning, fat atrophy and pigment changes. Other therapy that have been recommended with variable outcomes include injections of 5-fluorouracil [16] and bleomycin [17], laser therapy [18], radiotherapy [19], cryosurgery [20] and debulking with intralesional injection of methotrexate [21].

Corticosteroids were proved to induce scar regression through many different actions. First, they repress inflammation by inhibiting monocyte and leukocyte migration and phagocytosis [22], second, they have an antimitotic effect that impedes fibroblasts and keratinocytes, slowing reepithelialization and new collagen formation. Third, they are powerful vasoconstrictors, thus reducing the conveyance of oxygen and nutrients to the wound bed [22].

Zinc, is an essential micronutrient for humans and its importance can be gauged from the fact that it is an essential component of more than 300 metalloenzymes and over 2000 transcription factors that are needed for regulation of lipid, protein and nucleic acid metabolism and gene transcription [23]. Sharquie introduced oral zinc sulfate widely in treatment different and diverse skin diseases such as cutaneous leishmaniasis [24], basal cell carcinoma [25], plane warts [26], xeroderma pigmentosum [27] and others [28,29,30,31].

Also he used zinc sulfate in treatment of many skin sclerosing conditions like morphea, lichen sclerosus et atrophicans and different types of scars including hypertrophic and keloid [32].

From extensive reviewing literature, we found that there is no marked limiting factor between hypertrophic scar and keloid. Hence we prefer to use the term burn scar to include both hypertrophic scar and keloid.

So, the aim of this present study to record all cases of burn scar that followed burn as early as possible and treat them by medical therapy before any plastic intervention.

\section{Materials and Methods}

This case series descriptive and therapeutic interventional study that was carried out during the period from April 2014 to July 2020 where a total of 170 patients with burn scar were managed and evaluated. Their ages ranged from 1-40 years with a mean 25 year, $120(70.58 \%)$ males and 50 (29.41\%) females. All had a history of burn and the age of the scar was ranged from 0.5 -three years. Most patients mentioned that the scar appeared few weeks after healing 
of burn. The number of scars was often multiple and variable in size. The sites were face and neck in 68 (40\%) cases, limbs in 144 (84.7\%), while trunk in 64 (37.64\%) of patients.

All cases enrolled in the present study had no history of therapy with topical or systemic remedies for at least two months before starting the current work.

A full history was taken with emphasis on age, sex, duration of scar, associated symptoms, previous scar treatment and past medical and surgical history. A careful physical examination was carried out to identify the site, size, type, and color of the scars.

Formal written consent was taken for each patient before starting the therapy, after a full explanation about the nature of the disease, course, the method of treatment, complications, follow, prognosis, and the need for photographs before treatment and each visit during the following.

All patients were treated with topical diluted clobetasol propionate ointment (clobetasol ointment 0.05\% 50 gm + vaseline ointment $25 \mathrm{gm}+$ salicylic acid $1.5 \mathrm{gm}$ ) twice a day under occlusion in some suitable sites combined with oral zinc sulfate $(5-10 \mathrm{mg} / \mathrm{kg} /$ day in two divided doses) with a duration of 2-4 months. The clobetasol propionate $0.05 \% \mathrm{w} / \mathrm{w}$ ointment $\left(\right.$ Promax $^{\circledR}$ ) is manufactured by Jamjoom Pharma.

A scoring system of reduction of burn scar was newly introduced and applied and three parameters of response were considered: scar size reduction, improvement of itching and pigmentation whether hyper or hypopigmentation. The reduction in scoring was estimated as mild (1-3), moderate (4-7) and marked reduction (811). Also percentage of reduction was assessed (Table 1).

This scoring is semi- parametric assessment and it was carried out before therapy, at two months and at four months of therapy.

Two dermatologists compared the photos of patients before and during follow-up besides the clinical evaluation using scoring system in Table 1.

Patient's satisfaction to response to the treatment was assessed as follow:

1) Full satisfaction.

2) Partial satisfaction.

3) No satisfaction.

\section{Statistical Analysis}

All statistical calculations were performed using a Statistical Package for the Social Science version 22. Data were statistically described in terms of range, mean, median, frequencies (no. of cases), percentage (\%), scar duration and male to female ratio. The $p$ value of $\leq 0.05$ was considered statistically significant.

So the total scores will be 11 and this could be divided into: Mild reduction (1-3); moderate reduction; (4-7) marked reduction (8-11). So scoring should be carried out before therapy, at two months and at four months of therapy.

\section{Results}

The results of this study showed $50 \%$ reduction in scar size at two months therapy and this was statistically significant reduction with $p$ value $\leq 0.001$. While at four months, there was $75 \%$ reduction rate in scar size and with a highly statistically significant reduction $p$ value $\leq 0.0001$. There was marked rapid reduction and clearance of hyperpigmentation during therapy while leukoderma showed slow response. While the total reduction of scar scoring was mild in 34 (20\%) of cases and moderate in 51 (30\%) and marked in 85 (50\%) of patients at the end of four months of therapy and these results were also highly statistically significant $p$ value $\leq 0.0001$.

Itching was the main symptom and was found in 118 (69.41\%) of patients.

There were no untoward effects from topical therapy such as allergy,dermal thinning or fat atrophy noticed during the course of the study.

Mild adverse effects were recorded due to oral zinc sulfate therapy, these adverse effects were mild and did not necessitate to stoppage of therapy. These were nausea in 55 (32.35\%) and mild epigastric pain in 25 (14.70\%) patients.

Photos of patients before and during follow up period were showed in Figures 1, 2, 3.

Full satisfaction was in 111 (65.29\%) patients while 59 (34.7\%) patients had partial satisfaction.

\section{Discussion}

Cutaneous burn scarring is a persistent medical problem and characteristically underlies post-burn physical and psychosocial

Table 1. Scoring system to assess burn scar response to medical therapy

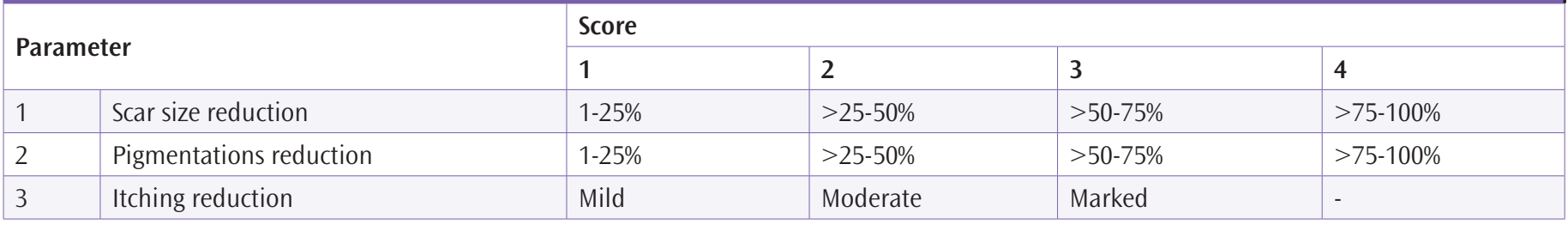



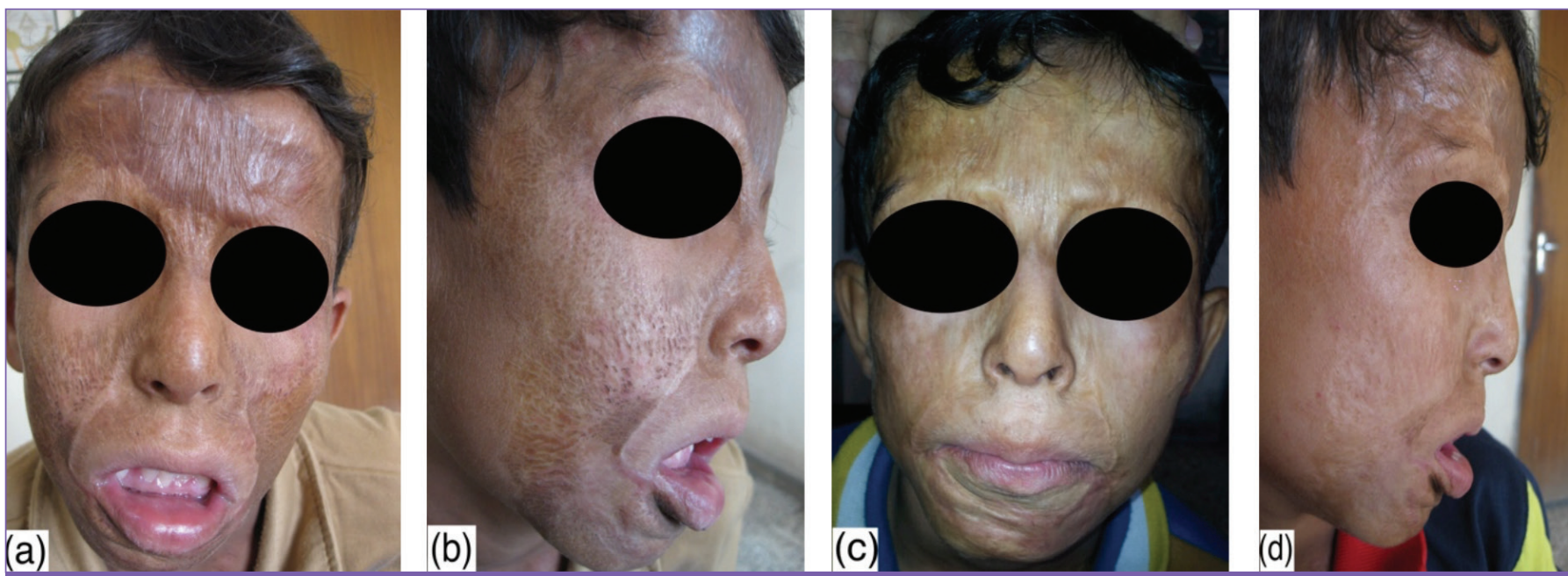

Figure 1. Twenty-three years old male with post burn scar of the face. Before treatment (a and b) and four months after treatment (c and d)

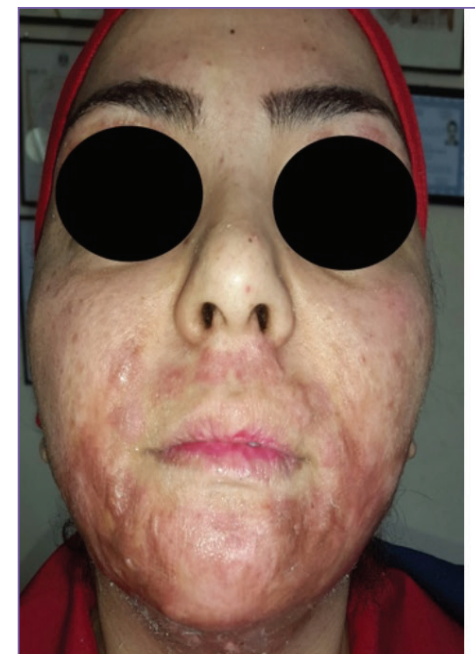

(a)
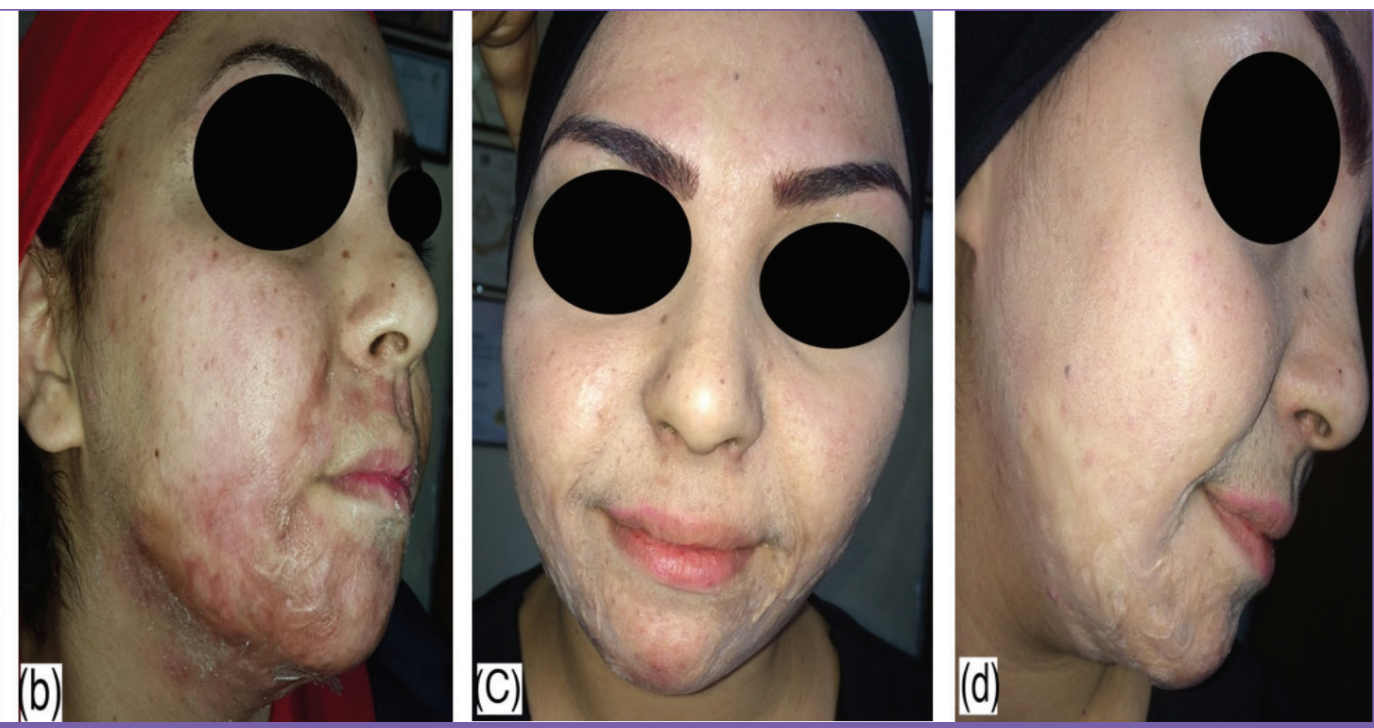

Figure 2. Thirty-seven years old female with post burn scar of the face. Before treatment (a and b) and four months after treatment (c and d)

morbidity [1]. The treatment of scars is challenging and needs multimodal management [33].

To our knowledge, the efficacy of topical diluted clobetasol ointment (clobetasol + vaseline + salicylic acid) has never been investigated in the treatment of scar but only one study by Atiyeh [34] demonstrated some efficacy of topical steroid in treatment of keloid, while another study recorded no effect [35].

Furthermore many previous studies pertaining to intralesional steroid alone or in combination with other therapy showed variable results with many side effects like high recurrence rate especially in keloid and many side effects such as pain at the site of injection, dermal thinning, fat atrophy and pigment changes [15].
The benefits of steroid in therapy of scars are by decreasing collagen/ glycosaminoglycan synthesis, inhibit leukocyte and monocyte activity, decrease in fibroblast activity via antimitotic activity, induce hypoxia via a vasoconstriction effect, increase in beta fibroblast growth factor and decrease in TGF- $\beta 1$ [22,36].

While topical salicylic acid causes desquamation of corneocytes as it dissolves the intercellular cement and reduces the $\mathrm{pH}$ of the stratum corneum, thereby increasing softening and hydration of epidermis [37]. Furthermore, it has antipruritic and anti-inflammatory actions and these actions may be explained by its inhibitory effects on prostanoids and cyclooxygenase. Also because of its keratolytic effects, salicylic acid increases the penetration of topical steroids $[38,39]$. 


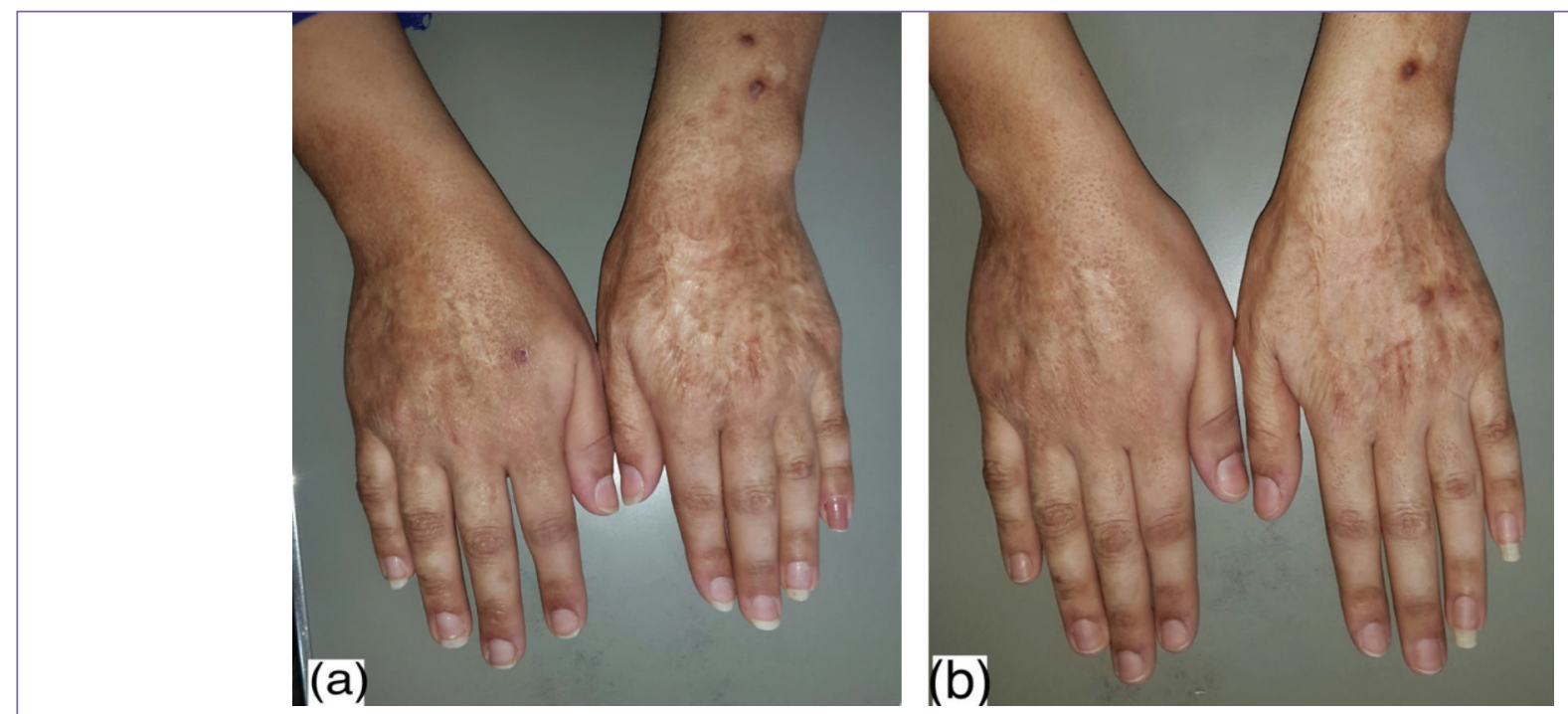

Figure 3. Twenty-one years old female with post burn scare of both hands. Before treatment (a) and after two months (b)

Petroleum jelly ointment (vaseline) when applied daily for 1-3 weeks are excellent alternatives to maintain wound bed moisture [40]. It enhances hydration of stratum corneum by reducing transepidermal water loss. Also, it has another benefit by decreasing scar erythema [41].

Sharquie introduced oral zinc sulfate in the treatment of morphea,lichen sclerosus et atrophicans and different types of scars since 1985 [32] and this work had encouraged us to conduct the present work by using oral zinc sulfate in addition to diluted topical and clobetasol ointment. The beneficial effect of topical zinc in the management of scar has been attributed to its capability to enhance collagenase and prevent lysyl oxidase that leads to increased degradation and decreased production of collagen. Moshref [42] recorded a complete clearance of keloids with a very low rate of recurrence in $34 \%$ cases with the application of a zinc tape. Similarly, Söderberg et al. [43] recorded a clinical improvement in 23 of the 41 cases with keloids after six months of application of a zinc tape.

From these different mechanisms of the different medications mentioned above in addition to our experience with the oral zinc sulfate in the treatment of different skin disorders, we encouraged to conduct the current study by using these combinations to get a synergistic effect, short duration of treatment, low recurrence rate, with minimal or no side effects.

Also, occlusive therapy enhances percutaneous absorption of clobetasol ointment and shows more potent action [44]. Besides, occlusion prevents transepidermal water loss and promote hydration of stratum corneum. Finally, pressure effects of the occlusion cause vasoconstriction which leads to hypoxia and this hypoxia decreases the scar size and prevents it from growing more or increase in size $[45,46,47]$.
Surgical treatment of scar is costly, associated with risk of infection, needs good experience in the treatment of scar, high recurrence rate especially with keloid or when it is used alone. In addition, the scar may develop at the donor site when grafting is indicated and sometimes need general anesthesia [48]. The results of this surgical maneuver is in contrast to results of current work using combination therapies as they are non-costly, easy to use, no risk of infection, $75 \%$ reduction rate in scar size with $50 \%$ reduction in scar scoring after four months of therapy. And with marked clearance of pigmentation and itching, these reductions were statistically significant. Also $64.7 \%$ of patients showed full satisfaction with no or mild side effects.

We believe that this innovative treatment regimen is a useful alternative to surgical intervention for post burn scar especially in early cases.

So the message from this present study is to encourage using nonsurgical approaches as early as possible including the combination of therapy as applied in this study. And to postpone surgical intervention (unless it is urgent) and give time for these medical treatments to exert their effects on burn scar, as medical treatments may show good therapeutic outcome.

\section{Study Limitation}

In our study, biopsy was not performed as it was refused by all patients.

\section{Conclusion}

Diluted clobetasol propionate ointment under occlusion combined with oral zinc sulfate is an effective mode of therapy for burn scar with mild or no side effects. 
Medical therapeutic intervention should be started as early as possible to minimize scar formation, to reduce the scar size and treat pigmentary problems. The present therapeutic protocol gave satisfactory responses in all patients and will minimize plastic surgery need. Also the present work introduced new scoring system that used to assess the response to therapy.

\section{Ethics}

Ethics Committee Approval: The study followed the Declaration of Helsinki Principles and it was approved by the Ethics Committee of Fallujah Teaching Hospital (approval number: 425, date:10/11/2020).

Informed Consent: Consent form was filled out by all participants.

Peer-review: Externally and internally peer-reviewed.

\section{Authorship Contributions}

Surgical and Medical Practices: K.E.S., R.I.J., Concept: K.E.S., R.I.J., Design: K.E.S., R.I.J., Data Collection or Processing: K.E.S., R.I.J., Analysis or Interpretation: K.E.S., R.I.J., Literature Search: K.E.S., R.I.J., Writing: K.E.S., R.I.J.

Conflict of Interest: No conflict of interest was declared by the authors.

Financial Disclosure: The authors declared that this study received no financial support.

\section{References}

1. Bombaro KM, Engrav LH, Carrougher GJ, Wiechman SA, Faucher L, Costa BA, Heimbach DM, Rivara FP, Honari S. What is the prevalence of hypertrophic scarring following burns? Burns 2003;29:299-302.

2. Tredget EE, Levi B, Donelan MB. Biology and principles of scar management and burn reconstruction. Surg Clin North Am 2014;94:793-815.

3. Trace AP, Enos CW, Mantel A, Harvey VM. Keloids and Hypertrophic Scars: A Spectrum of Clinical Challenges. Am J Clin Dermatol 2016;17:201-223.

4. Finnerty CC, Jeschke MG, Branski LK, Barret JP, Dziewulski P, Herndon DN. Hypertrophic scarring: the greatest unmet challenge after burn injury. Lancet 2016;388:1427-1436.

5. Profyris C, Tziotzios C, Do Vale I. Cutaneous scarring: Pathophysiology, molecular mechanisms, and scar reduction therapeutics Part I. The molecular basis of scar formation. J Am Acad Dermatol 2012;66:1-10;quiz 11-2.

6. Martin P, Nunan R. Cellular and molecular mechanisms of repair in acute and chronic wound healing. Br J Dermatol 2015;173:370-378.

7. Berman B, Maderal A, Raphael B. Keloids and Hypertrophic Scars: Pathophysiology, Classification, and Treatment. Dermatol Surg 2017;43:3-18.

8. Wang J, Hori K, Ding J, Huang Y, Kwan P, Ladak A, Tredget EE. Toll-like receptors expressed by dermal fibroblasts contribute to hypertrophic scarring. J Cell Physiol 2011;226:1265-1273.

9. Werner S, Grose R. Regulation of wound healing by growth factors and cytokines. Physiol Rev 2003;83:835-870.

10. Gurtner GC, Werner S, Barrandon Y, Longaker MT. Wound repair and regeneration. Nature 2008;453:314-321.

11. Gauglitz GG, Korting HC, Pavicic T, Ruzicka T, Jeschke MG. Hypertrophic scarring and keloids: pathomechanisms and current and emerging treatment strategies. Mol Med 2011;17:113-125.
12. Kim S, Choi TH, Liu W, Ogawa R, Suh JS, Mustoe TA. Update on scar management: guidelines for treating Asian patients. Plast Reconstr Surg 2013;132:1580-1589.

13. Anzarut A, Olson J, Singh P, Rowe BH, Tredget EE. The effectiveness of pressure garment therapy for the prevention of abnormal scarring after burn injury: a meta-analysis. J Plast Reconstr Aesthet Surg 2009;62:77-84.

14. Stavrou D, Weissman O, Winkler E, Yankelson L, Millet E, Mushin OP, Liran A, Haik J. Silicone-based scar therapy: a review of the literature. Aesthetic Plast Surg 2010;34:646-651.

15. Boutli-Kasapidou F, Tsakiri A, Anagnostou E, Mourellou O. Hypertrophic and keloidal scars: an approach to polytherapy. Int J Dermatol 2005;44:324-327.

16. Fitzpatrick RE. Treatment of inflamed hypertrophic scars using intralesional 5-FU. Dermatol Surg 1999;25:224-232.

17. Reddy R, Harinatha S, Raghunath $\mathrm{N}$. The role of Bleomycin in management of hypertrophic scars and keloids-A clinical trial. Our Dermatol Online 2015;6:404-406.

18. Ouyang HW, Li GF, Lei Y, Gold MH, Tan J. Comparison of the effectiveness of pulsed dye laser vs pulsed dye laser combined with ultrapulse fractional $\mathrm{CO} 2$ laser in the treatment of immature red hypertrophic scars. J Cosmet Dermatol 2018;17:54-60.

19. van Leeuwen MC, Stokmans SC, Bulstra AE, Meijer OW, Heymans MW, Ket JC, Ritt MJ, van Leeuwen PA, Niessen FB. Surgical Excision with Adjuvant Irradiation for Treatment of Keloid Scars: A Systematic Review. Plast Reconstr Surg Glob Open 2015;3:e440.

20. Har-Shai Y, Amar M, Sabo E. Intralesional cryotherapy for enhancing the involution of hypertrophic scars and keloids. Plast Reconstr Surg 2003;111:1841-1852.

21. Sharquie KE, Noaimi AA, Al-Karhi MR. Debulking of keloid combined with intralesional injection of methotrexate and triamcinolone versus intralesional injection of methotrexate and triamcinolone. J Clin Dermatol Ther 2014;1:003.

22. Roques C, Téot L. The use of corticosteroids to treat keloids: a review. Int J Low Extrem Wounds 2008;7:137-145.

23. Bibi Nitzan Y, Cohen AD. Zinc in skin pathology and care. J Dermatolog Treat 2006;17:205-210.

24. Sharquie KE, Al-Azzawi K. Intralesional therapy of cutaneous leishmaniasis with 2\% zinc sulphate solution. J Pan Arab League Dermatol 1996;7:41-46.

25. Sharquie KE, Al-Nuaimy AA, Al-Shimary FA. New intralesional therapy for basal cell carcinoma by 2\% zinc sulphate solution. Saudi Med J 2005;26:359361.

26. Sharquie KE, Khorsheed AA, Al-Nuaimy AA. Topical zinc sulphate solution for treatment of viral warts. Saudi Med J 2007;28:1418-1421.

27. Sharquie KE, Noaimi AA, Kadir NO. Topical Therapy of Xeroderma Pigmentosa with $20 \%$ Zinc Sulfate Solution. The Iraqi Postgraduate Medical Journal $2008 ; 7: 231-236$

28. Sharquie KE, Al-Mashhadani SA, Salman HA. Topical 10\% zinc sulphate solution for treatment of melasma. Dermatol Surg 2008;34:1346-1349.

29. Sharquie KE, Hayani RK, Al-Dori WS, Sharquie IK, Noaimi AA. Treatment of pityriasis versicolor with topical 15\% zinc sulfate solution. In 15th Congress of EADV, 2006; Abstract no. 950962.

30. Sharquie KE, Noaimi AA, Al-Salih MM. Topical therapy of acne vulgaris using $2 \%$ tea lotion in comparison with $5 \%$ zinc sulphate solution. Saudi Med J 2008;29:1757-1761.

31. Sharquie KE, AI-Mashhadani SA, Noaimi AA, Hasan AA. Topical zinc sulphate (25\%) solution: a new therapy for actinic keratosis. J Cutan Aesthet Surg 2012;5:53-56 
32. Sharquie KE. Iraqi society of dermatology and venereology activities. IMCAS 2017. Available from: http://www.imcas.com

33. Waibel JS, Wulkan AJ, Shumaker PR. Treatment of hypertrophic scars using laser and laser assisted corticosteroid delivery. Lasers Surg Med 2013;45:135140.

34. Atiyeh BS. Nonsurgical management of hypertrophic scars: evidence-based therapies, standard practices, and emerging methods. Aesthetic Plast Surg 2007;31:468-492.

35. Riaz Y, Cook HT, Wangoo A, Glenville B, Shaw RJ. Type 1 procollagen as a marker of severity of scarring after sternotomy: effects of topical corticosteroids. J Clin Pathol 1994;47:892-899.

36. Niessen FB, Spauwen PH, Schalkwijk J, Kon M. On the nature of hypertrophic scars and keloids: a review. Plast Reconstr Surg 1999;104:1435-1458.

37. Lebwohl M. The role of salicylic acid in the treatment of psoriasis. Int J Dermatol 1999;38:16-24.

38. Yosipovitch G, Sugeng MW, Chan YH, Goon A, Ngim S, Goh CL. The effect of topically applied aspirin on localized circumscribed neurodermatitis. J Am Acad Dermatol 2001;45:910-913.

39. Tiplica GS, Salavastru CM. Mometasone furoate $0.1 \%$ and salicylic acid $5 \%$ vs. mometasone furoate $0.1 \%$ as sequential local therapy in psoriasis vulgaris. Eur Acad Dermatol Venereol 2009;23:905-912.

40. Trookman NS, Rizer RL, Weber T. Treatment of minor wounds from dermatologic procedures: a comparison of three topical wound care ointments using a laser wound model. J Am Acad Dermatol 2011;64:8-15.
41. Commander SJ, Chamata E, Cox J, Dickey RM, Lee El. Update on Postsurgical Scar Management. Semin Plast Surg 2016;30:122-128.

42. Moshref S. Topical zinc oxide adhesive tape for keloid management. The Egyptian Journal of Surgery 2006;25:169-177.

43. Söderberg T, Hallmans G, Bartholdson L. Treatment of keloids and hypertrophic scars with adhesive zinc tape. Scand J Plast Reconstr Surg 1982;16:261-266.

44. Riley K. Flurandrenolone (Cordran) tape as occlusive therapy. J S C Med Assoc 1969;65:171-172.

45. Niessen FB, Spauwen PH, Robinson PH, Fidler V, Kon M. The use of silicone occlusive sheeting (Sil-K) and silicone occlusive gel (Epiderm) in the prevention of hypertrophic scar formation. Plast Reconstr Surg 1998;102:1962-1972.

46. Marks R, Sawyer M. Glucocorticoid-induced vasoconstriction in human skin. An inhibitory role on phospholipase A2 activity. Arch Dermatol 1986;122:881883.

47. Engrav LH, Heimbach DM, Rivara FP, Moore ML, Wang J, Carrougher GJ, Costa B, Numhom S, Calderon J, Gibran NS. 12-Year within-wound study of the effectiveness of custom pressure garment therapy. Burns 2010;36:975-983.

48. Ogawa R. The most current algorithms for the treatment and prevention of hypertrophic scars and keloids. Plast Reconstr Surg 2010;125:557-568. 